\title{
Narración y Metalenguaje en Grande Sertão: Veredas
}

Grande sertão: veredas presenta características especiales a nivel de la narración que la singularizan en la literatura brasileña. En esta novela, la comunicación narrativa, que explicita su articulación sobre un donante y un destinatario, alcanza un grado tan extraordinario de realización poética que no sería exagerado afirmar que representa una suma de experiencias narracionales de la ficción universal.

Este trabajo se propone investigar los problemas de emisión y recepción del relato, operando sobre dos códigos de significantes: cómo el narrador ve su historia y cómo el lector percibe lo narrado. En cuanto al primero, nos parece relevante coordinarlo con el metalenguaje del narrador Riobaldo, o sea: mostrar cómo el narrador dice que ve su historia. En el segundo código, será preciso mostrar cómo el lector es significado a lo largo del texto. El estudio del nivel narracional se ocupa, pues, como define Roland Barthes en su teoría narrativa, "de los signos de la narratividad, conjunto de operadores que reintegran funciones y acciones en la comunicación narrativa" '.

El punto de partida es saber quién narra en Grande sertão. Esto es aparentemente fácil: es Riobaldo, un personaje de la historia narrada. Pero es preciso calificar a ese narrador y diferenciarlo del autor:

a) Quien emite el relato no es una "persona", en el sentido psicológico de la palabra, portanto no se confunde con el autor. La novela no es la expresión de un "yo" exterior al texto;

b) Como los personajes, el narrador es un "ser de papel";

c) Los signos de ese narrador son accesibles a un análisis semiológico, ya que él es una "persona linguística". Lo que interesa es su "performance" en cuanto tal (su acto de elocución, la lexis).

\section{ELCODIGO DEL NARRADOR}

\subsection{Aspectos del relato (signos de la enunciación)}

El sistema de narratividad predominante en Grande sertão es, sin duda, el signo personal (yo). Decimos predominante y no exclusivo, porque hay 
secuencias que contienen la instancia a-personal (él), como por ejemplo en el episodio del Juicio de Zé Bebelo. Allí el discurso es directo e indirecto, alternadamente, y cuando indirecto, el narrador es más observador de los hechos que actuante en ellos.

Hay, también, otro aspecto de esa personalidad que debe tenerse en cuenta: al ser memorialístico, el relato distancia al narrador del actor de los acontecimientos. La situación actual del narrador está informada en el relato, en la instancia del presente de la locución. Riobaldo-narrador está viejo $^{2}$ y reumático (p.23), y practica el tiro al blanco para distraerse (p.9). Se considera un hombre ignorante (pp.152 y 234), pero paga tributo a la sabiduría del compadre Quelemém (pp. 152 y 348) y a la educación de su interlocutor (pp. 22,49,78,178). Suele hablar poco, le gusta pensar y repensar (p.234) y los recuerdos ocupan totalmente su existir (p.341). Está bien casado con una señora que se llama Otacilia (p.457), pero no se refiere a ningún hijo; nutre por su esposa una "amistad de afecto" (p. 394) y se vanagloria: "Conseguí pensar correcto: pienso como un río anda: que ni veo los árboles de las orillas..." (p.260). La religión es para él una suerte de solaz: " El rezo sí que saca la locura (...) Mucha religión, don muchacho! Yo aquí, no pierdo ocasión de religión. Aprovecho todas. Bebo agua de todos los ríos...Una sola es poco para mí, tal vez ni me alcance" (p.15). Tiene muchas dudas, $y$, tal vez, sólo una gran certeza: vivir es muy peligroso. Disfruta de la vida tranquila,"en el rechinar de la red"(p.11) o en su silla mecedora (sentado en ella cuenta su historia al doctor), y poco pretende ya: "Hoy lo que quiero es la fe, más la bondad (...) quiero mezclar la masa con mis manos y verla crecer y crecer... Otra razón, otros tiempos" (p.412).

Esta objetivación del pasado está estructurada a través de un artificio muy feliz, que es la colocación de una narrativa-marco ${ }^{3}$ que encierra la historia contada. $Y$ esto tiene importantes consecuencias para la percepción de lectura: si ésta se da al nivel de los acontecimientos en sí, hay personalidad del narrador, pero si se da al nivel del presente de la narración, objetivado el actor, prevalece la a-personalidad ${ }^{4}$. Por esta razón podemos afirmar que Grande sertão es un relato donde se mezclan los sistemas de narratividad, según la perspectiva del lector, móvil que obedece a los propios elementos significantes de la obra.

Según Kayser, una "situación épica primitiva" implica una tríada formada por el narrador, la materia narrada y el público, y la "actitud narrativa" es la "relación del narrador con el público y con la materia narrada" 5 . Barthes retoma la idea, definiendo la "situación de relato" como "un conjunto de protocolos según los cuales se consuma el relato" ". A pesar de admitir que el narrador es conditio sine qua non de toda literatura épica y que las actitudes narrativas están bien diferenciadas en la prosa, Kayser no cree en la eficacia de una tipología de las mismas para una teoría de los géneros épicos (y lo justifica a través de una fórmula vaga: "Porque la Epica es patentizadora de mundo") ${ }^{7}$. Sin embargo, cualquier esfuerzo por admitir 
la epicidad de Grande sertão choca con el problema de la narración. Por otro lado, en esta novela está representada la situación de relato, al contrario de la narrativa realista-tradicional que busca "disfrazar" el código narracional ${ }^{8} \quad y$, como en toda narrativa, el nivel narracional corona los niveles anteriores, cierra el relato y contiene el metalenguaje de esa misma narrativa ${ }^{9}$. Sólo que en $G$ rande sertão, este metalenguaje no es implícito, o meramente indiciado, sino que es explícito y claro, ofrecido por la polarización presente / pasado y conducido por el narrador en la evaluación que él mismo hace de su acto de elocución.

Ahora bien, si lo narrado en la épica se presenta como inmutable y fijo ${ }^{10}$ esta valoración altera la "pureza" del aoristos, que es la mejor expresión linguíística de lo épico, haciéndolo mutable y móvil. Aunque podamos establecer varios elementos de identificación en Grande sertão con la épica (independencia de ciertos fragmentos, el acontecimiento que da orientación al relato, el héroe soporte al que se subordinan los acontecimientos, la amplitud del espacio, etc), la personalidad de la narración impide la elevación de Riobaldo a las alturas de rapsoda. Aunque no haya particularización del mundo del relato (el sertão es un "cosmos"), ni particularización del lector (los "valores" de la obra son universales) - sin embargo, el tono es particular, y esto volatiliza la epicidad de Grande sertão.

La representación de la situación de relato, como el enfrentamiento narrador/interlocutor, destruye la necesaria distancia exigida por la Epica. Riobaldo-narrador asume una franca actitud de confesión y ni remotamente hace el papel de intermediario de las Musas, o se conduce con solemnidad homérica.

\subsection{Un protocolo de presentación: la narrativa-marco}

Dijimos que Grande sertão representa su situación de relato. Efectivamente existe una situación plenamente: interrelacionamiento de personajes, relaciones mutuas espacial y temporalmente configuradas, y es la siguiente: un ex-jagunço llamado Riobaldo, al contar la historia de su vida (como jagunço* de varios jefes y él mismo como jefe) y sus amores, a un "doctor" de la ciudad, a quien hospeda en su casa, por tres días, se pregunta con respecto a la existencia del demonio y solicita a éste último que lo ayude a encontrar la respuesta. Se puede figurar la imagen de un cuadro, cuya tela fuese la historia contada por Riobaldo, y cuyo marco estuviese constituído por el acto de contarla. Los componentes de cada una de esas narrativas son nítidos y las podemos esquematizar de la siguiente manera:

Narrativa "A":

1. Acción: historia de la vida del jagunço Riobaldo;

2. Personajes: Riobaldo, Diadorim, Zé Bebelo, Medeiro, Vaz, Joca, Ramiro, etc. 
3. Tiempo representado: varios años: desde el encuentro con el niño Reinaldo, en las márgenes del Río San Francisco, hasta la muerte de Diadorim.

4. Espacio representado: el sertão (con especificación de varios lugares).

5. Tiempo verbal: pretérito (imperfecto y perfecto).

6. Tipo de discurso: indirecto.

Narrativa " $B$ ":

1. Acción: el contar ciertos acontecimientos vividos por un jagunço.

2. Personajes: el viejo Ribaldo y un doctor de la ciudad.

3. Tiempo representado: tres días (igual al tiempo de locución de A.1).

4. Espacio representado: la casa de Riobaldo.

5. Tiempo verbal: presente.

6. Tipo de discurso: directo.

La narrativa " $B$ " contiene a " $A$ " y confrontándolas se ve que son diferentes en cuanto a la "situación narrativa". Según Stanzel, habría dos, por lo tanto, también habría dos tipos de novela"11:

"A" - situación narrativa del "yo": se identifican el yo-narrador con el yo que vive la experiencia, pero se distancian temporalmente (novela en primera persona).

"B" - situación narrativa personal: la representación es escénica, fijándose el "hic et nunc" de los personajes (novela de personaje).

Examinemos en esta novela un modelo del montaje de las dos situaciones y las "performances" narrativas de cada una:

Pero yo miraba a ese niño, con un placer de compañía, como jamás por nadie había sentido. Me parecía que él era muy distinto, me gustaron aquellas facciones tan finas, la voz misma, muy leve, muy apacible (...). Fuí recibiendo en mí un deseo de que él no se fuese nunca más de allí, sino que se quedase, sobre las horas, y así como estaba siendo, sin charla barata, sin bromas - sólo mi compañero amigo desconocido. Escondido enrrollé mi bolsa, ahí mismo, a pesar de la fe en la promesa tuve vergüenza de estar pidiendo limosna. Pero él apreciaba el trabajo de los hombres, llamando a ellos mi mirada, con una manera sesuda. Sentí, manera mía de niño, que él también ya simpatizaba conmigo (p.81).

Este pasaje de la historia corresponde al grado cero del sistema temporal representado en la novela: es el primer encuentro de Riobaldo con el niño Reinaldo, en las márgenes del Río San Francisco. La situación narrativa es francamente de primera persona (el narrador y el personaje se 
identifican pero no se confunden), con los indicadores: yo, me, mío, mía, conmigo: la modalizacón expresa la no-omnisciencia ("sentí que...", "me parecía que..."); sólo hay ciencia en el ámbito del "yo", con verbos de estados interiores: sentir, parecer, gustar, desear, avergonzarse. Todorov observa que en relatos que dicen "yo", hay un "sujeto de la enunciación enunciado", que se intercala entre el "él" y el "yo" ("me") y que los sumerge, sin destruirlos. En "yo miraba", por ejemplo ese "yo" que miraba no es el mismo que el que enuncia. " $Y o$ no reduce dos a uno, sino que convierte dos en tres" 12 .

El trozo arriba transcrito es seguido por una descripción de los acontecimientos de la travesía del río, la que, una vez completada la presentación de los hechos, es sucedida por la evaluación actual de los mismos:

Ahora que usted oyó, le hago preguntas: ¿Por qué fue que yo tenía que encontrar a aquel Niño? Tonterías, yo se. Doy, de.Usted no me conteste. (...) Pero cuando es una bobada dar cualquier respuesta, es ahí que la pregunta se pregunta. ¿Por qué fue que yo conocí a aquel Niño? Usted no lo conoció, mi compadre Quelemém no lo conoció, millones de millares de personas no lo conocieron. Usted piense otra vez, repiense bien lo pensado: ¿para qué fue que yo tuve que atravesar el río, frente a frente con el Niño? (...) Pero, ¿para qué? ¿por qué (...)? De veras se ve que el vivir de uno no es tan cosidito así? (...) ¿Lo qué? No me dé no. Pero hoy más mañana, va a ver que usted me da una respuesta. Así, usted ya me da gusto. Ahora por la manera de callarse tanto, veo que usted me interpreta. (pp.86-87).

Aquí, un ejemplo de la segunda narrativa. La narración abandona el pretérito y fija el presente. Allí se dice "ahora" y, como en el ejemplo de "A", dos personajes se enfrentan: el narrador y un "usted" a quien aquél propone una questión pero no lo deja responder. Con todo, la forma monológica es apenas una apariencia, ya que el interlocutor da una respuesta de asentimiento al "usted no me conteste" y sus signos estarán dados por el locutor del mensaje en el curso del diálogo (véase más adelante 3.1.). La narración hecha en el modo dramático registra actos, gestos y palabras de los participantes en la escena, mostrándolos, sin mediación. Otro aspecto es también notable: la narrativa " $\mathrm{A}$ " aparece en relación de subordinación con la narrativa "B". Desde la primera página de la novela, "B" no tiene autonomía, es dependiente de la principal que le antecede (lo que significa que tenga más "valor"). Lingüísticamente diríamos que no hay equivalencia entre ellas, sino dependencia, donde " $A$ " es el núcleo subordinante, oración principal, y " $\mathrm{B}$ " su complemento, oración subordinada o accesoria. La misma articulación sintagmática de la narrativa coloca a " $B$ " siempre como consecutiva y consecuente de " $A$ ".

La narrativa que llamamos " $B$ " es la situación de relato. En una primera 
instancia es un análisis de los acontecimientos relatados en "A", para ser después un balance de la actual situación del narrador. Semánticamente, " $B$ " se presenta, en relación al núcleo, como deducción, conclusión, generalización, indagación, explicación, etc. Pero este marco logra otro estrato si distinguimos la evaluación del hecho de la evaluación del acto (de narrar). La crítica de Guimarães Rosa siempre se ha orientado hacia esa característica especial de la novela: Cavalcanti Proença propuso una división en plano objetivo y subjetivo ${ }^{13}$, y José Carlos Garbuglio distingue dos planos: 1o) el diacrónico (la historia); 2o) el sincrónico, con una subdivisión de este en: a) especulación existencial y b) metalingüístico ${ }^{14}$. Queremos agregar aquí algunas consideraciones sobre esta división para abrir camino al problema que nos interesa: la visión crítica del narrador sobre el acto de narrar.

Así, admitiendo niveles de la narrativa " $B$ ", podemos formular:

A - presentación de los acontecimientos (pretérito).

B - representación del diálogo; se subdivide en:

$B_{1}$ - evaluación del acontecimiento relatado en $A$ (el pasado)

$B_{2}$ - evaluación de la vida actual del narrador y de la condición humana (el presente)

$B_{3}$ - evaluación del acto de narrar (el presente en progresión)

Con un ejemplo se puede visualizar mejor la articulación de los niveles:

A - "Desistir de Diadorim,

$B_{3}-i$ fue lo que yo dije? Digo, desdigo. Puede hasta que, por mi descuido para contar, usted esté creyendo que, en la rancheada del campamento, yo poco viese a Diadorim, la amistad nuestra padeciese de descuido o mengua. Engaño. Todo al revés.

A - Diadorim y yo, estábamos siempre al alcance de la voz y al alcance de los ojos, constante uno no muy lejos del otro. De la mañana a la noche, la afección nuestra era de un color y de una pieza. Diadorim, siempre atento, listo, correcto en su buen proceder. Tan seguro de sí, él alejaba cualquier mal estado de ánimo mío.

$B_{3}-$ ¿Por qué es, entonces, que yo me salteo eso, en resumen, como no debía de, en esta charla mía abreviada? Vea, señor, lo que es mucho y mil: me estoy equivocando. Si estuviese contándole a usted, en detalle, solamente lo que Diadorim vivió presente en mí, el tiempo-de tan repetido, igual, trivial - así sería que yo le explicaría a usted aquella verdadera situación de mi vida. ¿Por qué, entonces, es que yo la dejo de lado?

$B_{2}-\mathrm{Me}$ parece que el espíritu de uno es un caballo que elije el camino: cuando rumbea para la tristeza y la muerte, ya no va viendo lo que es bonito y bueno. ¿No?

$B_{3}-Y$ aquel Garanço, mire: lo que yo le dije, de bondad y amistad, no fue correcto. 
$B_{1}$-Sé que, aquella vez, no sentí. Sólo sentí y pensé el recuerdo,

$B_{2}$-que descubrí, después, de muchos años.

$\mathrm{B}_{1}$-Pobre Garanço,

A - él quería relatar, me hablaba: - "Fuí conductor de mulas, en el Serém. Tuve tres hijos..." etc. (pp. 143-144).

La combinación de estos niveles no se realiza por alternancia, pues no ocurre la mera interrupción de uno para pasar al otro, y, es obvio, no hay un modelo de repetición (tipo $A B_{1} B_{2} B_{3} A$ etc.); tampoco hay coordinación ${ }^{15}$, pues no existe una pura yuxtaposición de los niveles. Hay, sí, encaje, ya que la relación sintáctica es de subordinación(el núcleo siempre es de $A_{\text {para }} \mathrm{B}_{1}$ y $B_{2}$, pero para $B_{3}$ puede ser cualquiera y más de uno al mismo tiempo) y también tenemos la inclusión de una historia dentro de otra, de la misma forma como observó Todorov para Las mil y una Noches, cuyos cuentos se encajan en el cuento de Sherazada ${ }^{16}$. Podemos decir también que cada vez que ocurre A se abre una combinatoria. En el ejemplo citado hay dos tipos de combinación solamente. ¿Cuántos habrá en toda la novela? Imposible saberlo por cálculos matemáticos (el número de niveles combinados con $\mathrm{A}$ es variado). Lo importante es saber que el principio de relación entre ellos, que apuntamos arriba, se mantiene a lo largo de toda la novela.

\subsection{La oralidad del discurso de Riobaldo}

Ya se observó que Grande sertão no es un flujo de la conciencia, pues el diálogo instaura la "objetivación de las relaciones por medio de la lengua hablada" ${ }^{17}$. Al ser flujo oral, se aparta del irracionalismo de los estados preconscientes para ser lenguaje de la consciencia-formulada - y cuyo sentido surge de la secuencia de los segmentos ${ }^{18}$. Esa oralidad, aunque que se expresa, de inmediato, en el primer signo tipográfico de la novela, abriendo la representación del habla, va mucho más allá del mismo y consta de todo el metalenguaje de Riobaldo. Así, su acto narrativo está siempre referido como un habla:

Ahí, arre, pero si esta boca mía no tiene orden ninguno (p.19).

Bueno, como iba diciendo... (p. 20).

Si yo estoy hablando tontamente...(p.49).

Sé que esto que estoy diciendo ... (p.78).

Ahora que usted oyó...(p.86).

Me disculpe usted, sé que estoy hablando...(p.112).

.. lo que yo dije, ifue exacto? (p.142).

... en esta charla mía abreviada? (p.143).

De todo no hablo. (p.166).

... lo que venía diciendo. (p.234).

...usted me va a escuchar. (p.237).

...hablo para que usted crea... (p.261).

Usted, ya que oyó hasta aquí, siga oyendo. (p.288).

... ya vengo - hablaré del asunto (...) Y escuche. (p.370). 
Lo que me mortifica de tanto hablar...(p.385).

Etc., etc.

Hablar, decir, oír son denotadores de la oralidad del relato, como también lo son los recursos lípicos del lenguaje hablado (elipsis, anacolutos, repeticiones, etc.) y las expresiones "muletillas" de lo coloquial ( $a h i$, de ahi, y sobre todo, mire y vea). Además de hablar aparecen: referir, contar, relatar, narrar, glosar y hasta servir la narración (p.175) - cuando Riobaldo se refiere a su acto de elocución. Predomina, sin embargo, el término contar. La etimología de la palabra ayuda en este caso: contar viene de computare, "computar", "contar", "referir" (cuento viene de computum), y sólo posteriormente significó "relato de aventuras imaginarias". La acepción de contar como computar, calcular, se adapta al propósito del narrador de descubrir por la narración los ligamentos de los hechos, el por qué de las cosas (narrador = evaluador).

Esa oralidad contiene también otro problema: el habla es otorgada en Grande sertão por la escritura y esto crea una curiosa relación entre los opuestos: el cierre inherente a ésta, se diluye en aquélla. "Lo que opone la escritura al habla - nos dice Roland Barthes - es que la primera parece siempre simbólica, introvertida, vuelta ostensiblemente a una vertiente secreta del lenguaje, al paso que la segunda no pasa de ser una duración de signos vacíos, de los cuales sólo el movimiento es significativo" 19 . Grande sertão logra, así, neutralizar con la movilidad del habla el endurecimiento y la contra-comunicación de la escritura ${ }^{20}$.

Esta aventura lingüística es todavía una propuesta nueva en la tradición novelesca del Brasil, ya que "queda eliminado el contraste torpe, tan practicado por la prosa regionalista, entre el diálogo que reproduce el hablar y el no-diálogo que reproduce la práctica letrada del au tor" 21 .

\section{LA VISION CRITICA DEL NARRAR}

Riobaldo aparece en la novela en tres actuaciones básicas: 1) es personaje de "A" y personaje de "B"; 2) es narrador de "A", y 3) es crítico de su método de narrar en " $B$ ". Así, mientras el narrador hace del personaje su objeto, el crítico se vuelve a su vez sobre el narrador; de derecha a izquierda, este esquema muestra la relación sujeto-objeto:

$$
\text { Personaje (A y B }) \longleftarrow \text { narrador }(A) \longleftrightarrow \operatorname{critico}\left(B_{3}\right)
$$

La cuarta actuación de Riobaldo $\left(B_{3}\right)$ constituye su metalenguaje. Todo sistema de significación comporta un plano de expresión (E) y un plano de contenido (C) y se realiza con la relación $(R)$ entre (E) y (C): ERC. Sabemos que este sistema puede imbricarse en un segundo sistema en dos puntos distintos de inserción: (E) y (C); si la inserción se hace en (E), el resultado es un sistema de connotación: (ERC) RC; si se hace en (C) el resultado es un sistema de metalenguaje: E R (ERC) 22 . En Grande sertão se verifica la original coexistencia de dos sistemas dobles, donde " $A$ ", " $\mathrm{B}_{1}$ " $\mathrm{y}$ " $\mathrm{B}_{2}$ " forman 
el sistema de connotación y " $B_{3}$ " un sistema metalingüístico, que opera sobre el lenguaje del primero. Podemos representar el montaje de los sistemas de la siguiente manera:

\section{[(E R C) R C ] [ER (E R C)]}

Es también notable que en la evaluación del acto de contar su historia, Riobaldo-narrador, como un semiólogo, crea un sistema en que (C) está constituído por un sistema de significación. Ahora bien, por estar inserto en la obra y sin ser lenguaje científico, se ve en seguida que el sistema metalingüístico, se levanta como un nuevo sistema de connotación. La operación que realizamos en seguida quiere hacer de este metalenguaje un lenguaje-objeto, buscándole los significados y la pertinencia (eventual) con relación al primer sistema. En otras palabras, queremos examinar la poética de Riobaldo.

\subsection{El método es "desordenado"}

Riobaldo manifiesta, desde el comienzo y como primer paso para su autocrítica, plena conciencia de la subversión que maneja a la cronología de los hechos vividos: "Ahí, arre, pero si esta boca mía no tiene orden ninguno. Estoy contando fuera, cosas divagadas" (p.19). La justificación viene de inmediato:

Si estoy hablando tontamente, usted me corta. Mi modo es éste.

Sé que estoy contando mal, por lo alto. Desanudo (..) Y yo estoy contando así, porque es mi modo de contar. (...) El recuerdo de la vida de uno guarda en fragmentos distintos, cada uno con su signo y su sentimiento, (...) Contar seguido cosidito sólo si las cosas son de poca importancia. (pp. 77-78).

(...) sé que estoy contando de más, por los costados. Resbalo. Así es que la vejez hace. (p. 112).

Si lo que cuenta es "dificultoso, muy entrenzado" (p. 78) es imposible someterlo a la racionalidad de la cronología. Lo que cuenta "no es una vida de sertanejo [habitante del sertãol, ya sea de jagunço, pero sí la materia vertiente." (p.79).

Su aprendizaje de "contador" le debe mucho a Quelemém, el compadre, uno de los que ya oyeran su historia y "orientaron" a Riobaldo sobre la ordenación de la materia. Su gran contribución en este sentido fue designar al verdadero objeto de los relatos de Riobaldo:

... él quiere saber todo distinto: quiere no el caso enterito en sí, pero la sobre-cosa, la otra cosa. (p.162).

Por eso el narrador no va en busca del pasado, como un mero antecedente del presente. J.P. Vernant, al analizar los problemas de la creación poética en la Grecia antigua, observa que el poeta, poseedor de la ciencia de Mnemosyne, quiere conocer los "comienzos", los "orígenes", y el 
pasado es una "fuente" del presente. Este concepto de "poesis" se aplica a Riobaldo, pues él busca el pasado, y, tal como el poeta primitivo, su "recuerdo procura no situar los acontecimientos en un cuadro temporal, sino alcanzar el fondo del ser, descubrir el original, la realidad primordial de que proviene el cosmos y que permite comprender el acontecer en su conjunto" 23 .

Es significativo que esos comentarios sean más numerosos hasta la descripción del Encuentro con Reinaldo en las márgenes del San Francisco: es cuando encuentra el comienzo de su fábula que la percepción del desorden alcanza su más alto grado. Momento de la definición categórica del objeto de la narración (la materia-vertiente), es a partir de ahí que el crítico deja de comentar con insistencia la ruptura de la cronología de los hechos, aunque más tarde ocurran cortes y alteraciones del orden de los acontecimientos, como, por ejemplo, la proposición del enigma de Gramacedo al tropero, que está contada después de la mención de la reacción de Diadorim ante lo ocurrido (pp. 353-58) o el recibimiento de la herencia de Selorico Mendes, que es seguido del viaje a Itacambira (p.457). De cualquier modo, es evidente cierta linealidad, sobre todo a partir del juicio de Zé Bebelo. Allí el narrador emprende la corrección de su método y lo atribuye a la actitud de "devoción" de su interlocutor (p.152).

La dificultad de ordenar la materia surge de su propia naturaleza: no es la vida lo que quiere contar, sino el vivir (lo que vierte). Aquí, el crítico Riobaldo establece una interesante oposición entre el vivir y el contar ${ }^{24}$ : la racionalidad del discurso dificulta reproducir los movimientos del vivir:

Si uno pudiese narrar...(p.261).

Los días malos, el castigo del tiempo todo quedado, en qué fallamos en la Coruja, cuento malamente. Cualquier narración de esas depone en falso, porque lo extenso de todo sufrido se escabulle de la memoria (p.304) Apenas sé: jyo sentinela! Sólo no le puedo dar una descripción a usted, del estado en que yo pensé, supuse: sólo sé de lo básico. (400).

$Y$ hay una manera verdadera de contar las cosas - iuna vivencia de esas? (p.445).

Contar es siempre desvirtuar la realidad vivida, "enfriarla", vaciarla, hacer un "luiz-e-silva" (p. 448) de la complejidad y riqueza del vivir:

Pero cuento menos de lo que fue: en la mitad, por no contar el doble. (...) Hasta yo - que usted ya vio, doy vuelta a la retentiva con espejos cien - doble de luces, y todo, grande y menudo, guardo hasta yo no acierto a describir lo que se pasó así, pasamos, cercados guerreantes. (...) (p.260).

¿Cómo voy a contar, y usted sentir, en mi estado? ¿Usted sobrenació allí? ¿Usted mordió aquéllo? ¿Usted conoció a Diadorim, señor mío? ... (p. 449). 
Si las dimensiones del vivir están disminuídas por el contar, el recurso al detalle servirá para compensar tal vacío de la palabra. De ahí la segunda instancia del metalenguaje.

\subsection{El método es detallista}

El narrador Riobaldo es pródigo en detalles 25 - elementos accesorios a la descripción de los hechos - cuya funcionalidad está atenuada o es indirecta, y que a veces son esa especie de "lujo" de la narración, que Barthes verificó en ciertas catálisis. En Grande sertão, la memoria de Riobaldo llega a ser tan prodigiosa al punto de describir minuciosamente un acontecimiento, sus circunstancias, los accesorios de la situación, sus reacciones de entonces, etc. Sirva de ejemplo aquel combate con los Hermógenes, en que Riobaldo es llamado por Bebelo para escribir cartas a las autoridades; al describir el combate, el narrador destaca un objeto en el espacio de la acción - el cuero de buey colgado en la ventana de la casa y que se movía al contacto con las balas (pp.249-51). Sin querer discutir aquí las posibilidades de integración de esa unidad en la estructura de la novela (de inmediato hay una analogía entre la prestancia del cuero y el cuerpo del jagunço), queremos apenas destacar la función realista del detalle en el proceso de la narración. Roland Barthes, analizando la "significación de las notaciones insignificantes" en relatos realistas, propone un sentido para ellas: al ser una subordinación a las reglas culturales de la representación, o sea, al "imperativo realista" de la narrativa, provocan la "ilusión referencial" 26 . De esta forma, el recurso al detalle le sirve al narrador para el efecto de real, necesario para que el interlocutor confíe y crea en su relato. Todo debe parecer verdad y el narrador se empeña en eso, rellenandolos hechos. Pero, el Riobaldo-crítico surge en la escena para disculpar al narrador:

$\mathrm{Y}$ usted me disculpe, de estar retrasando en tantas menudencias.

Usted advierta el tanto decir (...) Es todo cuento, como está dicho. No me gusta olvidarme de nada. Olvidarme para mí es casi igual que perder dinero. (p.308).

¿Por qué se lo cuento todo a usted, de tantas cosas? (p. 431).

La minucia debe atestiguar una memoria excepcional:

A la hora de la hora, digo, afirmo que me acuerdo de todos. (...) No es por elogiarme de retentiva en que todo cabe, nombre por nombre, pero para limpiar la continuación de todo lo más que voy a narrar (...) (p.340)

o atestiguar la adecuación de la enunciación a la materia:

Digo franco: feo lo que pasó, feolo narrado (p. 389).

Sirve también el pormenor para prolongar el placer de la narración que hace revivir:

Todo esto, para usted, mi querido señor, no tiene sentido, ni vale la 
pena. Pero yo estoy repitiendo muy menudamente, viviendolo que me faltaba. Tantas cosas mezcladas yo sé (...) Y muchas cosas menudas acontecieron. (p. 401).

La busca del "efecto de real" puede todavía descuidar el potencial de la palabra y utilizar otros signos más eficaces:

Y bien, ¿cómo es que voy a dar, con letras, los datos del lugar, definir para usted? Sólo si hago uso de papel, con mucho dibujo. Usted forme una cruz, trácela. (p. 414).

Nada puede ser omitido en la descripción de una importante batalla:

Pero primero, antes, hubo el comienzo. Y ahí, hubo el antes-delcomienzo (p. 414)

\subsection{El método es digresivo}

Ocurren frecuentemente desvíos en la secuencia de los acontecimientos. El crítico,entonces, apunta la falla del narrador, como en este ejemplo, después de la digresión hecha sobre Zé Bebelo:

Pues, sin embargo, al fin retomo, enmiendo lo que venía contando (p.62).

Otro ejemplo está dado por el discurrir sobre Nhorinhá; Riobaldo advierte el desvío de los datos esenciales y dice:

Pero, y lo que yo estaba diciendo, pero aún pensando en Nhorinhá, con causa. (p. 395).

Pasajes importantes, como la expedición de regreso del Liso do Sussuarão, son interrumpidos para enfilar ideas sobre Dios y el Diablo (pp.47-49). Pero el narrador bruscamente corta la digresión para decir: "De Arassuaí, traje una piedra de topacio", y con esto retoma la fábula.

\subsection{El método es recurrente}

La enunciación, presente en progresión continua, permite el vaivén de ciertas palabras, frases y refranes, que constituyen verdaderos "motivos" de la narración ${ }^{27}$; hay también ideas, como la del demonio que tiene vigencia "en los pliegues del hombre" y también en la narrativa; o la del pacto con aquél; Riobaldo advierte la recurrencia:

...icómo es que se puede contratar pacto con él? Y la idea me vuelve (p. 33).

Usted sabe. Lo que mortifica de tanto hablar en él, usted sabe. El demonio!. (p. 385).

El estribillo de la novela es "vivir es muy peligroso". La repetición alcanza tal grado de saturación que el propio narrador se da cuenta a cierta altura, omitiendo la segunda mitad del enunciado:

Vivir... usted ya sabe: vivir es etcétera... (p. 74). 


\subsection{Elmétodo es memorialístico}

Prescindiendo de la diferenciación platónica entre "memoria" y "recuerdo" (reminiscencia) y otras precisiones filosóficas posteriores, usaremos el término memoria en el significado más inmediato: "objeto o facultad psíquica de actualización de la experiencia vivida", y recuerdo, "el proceso psíquico que ella desencadena", el cual, a su vez, nada tiene que ver con la corriente de la conciencia - término crítico que se aplica estrictamente a obras que exploran los niveles de la conciencia anteriores a la palabra y que no suponen ninguna forma de comunicación ${ }^{28}$.

Riobaldo dice recuerdo y me acuendo, al referirse a la operación que realiza, con dominio, sobre el pasado:

...usted ya vió que tengo retentiva que no falta, recuerdo todo (p.35)

Muestro para que usted vea que me acuerdo (p. 243).

Otras veces es consciente de las limitaciones de la memoria:

Contar es muy, muy difícil. No por los años que ya pasaron. Sino por la astucia que tienen ciertas cosas pasadas - de hacer vaivén, de revolverse de sus lugares. (p.142).

El correr de la vida enreda todo, la vida es así: calienta y enfría, aprieta y de ahí afloja, sosiega y después nos inquieta (p. 241).

El acto de contar permite evaluar el pasado, porque la memoria ayuda en la tarea de reconstrucción de lo vivido por la perspectiva del presente. "Pero en aquel tiempo yo no sabía. ¿Cómo es que yo podía saber?" (p.229). "Mismo lo que estoy contanto, después es que pude reunir acordándome y verdaderamente entendiendo (...)"(p. 108). La suma de experiencias vividas es la que suministra el balance: "El San Francisco partió mi vida en dos partes" (p.235). El viejo Riobaldo también sabe que acordarse es alterar el valor de los acontecimientos y relatarlos es, antes que nada, imaginarlos comprehensivamente ${ }^{29}$ : "Ahora que más viejo me veo, y cuanto más remoto aquello está, el recuerdo muda de valor - se transforma, se compone, en una especie recorrido hermoso"(p. 260).

\subsection{El método es selectivo}

$\mathrm{Si}$ en 2.2., la visión crítica de Riobaldo apuntaba a una idea de "realismo" ${ }^{30}$ en la presentación de los hechos, y si en 2.4. ya se indica la antítesis de esto en el proceso de análisis (la memoria perjudica la objetividad total), veremos ahora que toda imagen de fidelidad a lo vivido se destruye por el principio de selección de la materia. Riobaldo dice que su charla es "abreviada" (p. 143) y, como un teórico de la narrativa, sabe que narrar es seleccionar, depurar la materia, estructurarla para "encontrar el rumbocito fuerte de las cosas" (p. 135). Es curioso observar que, a medida que va contando, Riobaldo aprende a analizar su proceso de representación, de modo que su "teoría narrativa" es el feliz resultado de su práctica 
narrativa. Del punto de vista de la selección, su análisis del método suministra un ejemplo de la búsqueda de definición, o del sentido del ñarrar. Y esto se da en dos etapas: indagativa, en la cual la omisión de ciertos detalles o hechos se auto-justifica (predomina el para qué?), o obedece a una atribuición subjetiva de significado:

Pero, ¿para qué contarle a usted, en sus tintes, lo más que se mereció? Basta el bulto ligero de todo ( $\mathrm{p}$ : 44).

El recuerdo de la vida de uno se guarda en trechos diversos, cada uno con su signo y su sentimiento (...) Contar seguido, cosidito, sólo si las cosas no tienen importancia ninguna (pp. 77-78).

Usted sabe, se procede al revés: la acción resbaladiza y tensa, pero sin sustancia contable (p.106).

¿Para qué referir todo en el narrar, por menos y menor? (p.108).

De todo no hablo. No intenciono relatar a usted mi vida en pasos doblados; ¿para qué servía? (p.166).

En este punto ya se inicia la transición para la nueva etapa del análisis. Riobaldo da respuesta a su pregunta: "Lo que quiero es armar el punto de un hecho, para después pedirle un consejo" (p.166). Vuelve otra vez a preguntar para qué? y nuevamente responder:

Voy a reducir el contar (...) ¿Acaso eso merece que se cuente? Menudo y menudo, caso usted quiera, doy la descripción. Pero no anuncio valer. (...) Pero para mí, lo que vale es lo que está por debajo o por encima - lo que parece lejos y está cerca, o que está cerca y parece lejos. Le cuento a usted lo que yo sé y usted no sabe; pero principalmente, quiero contar lo que yo no sé si sé, y que puede ser que usted sepa. (p.175).

Al establecer la finalidad de su relato (pedir consejo o saber lo que no sabe), se organiza la segunda etapa del análisis de la selección: la explicativa (predomina el porque). Es el destino de la narración (el diálogo con el interlocutor) lo que justifica ahora la selección de los pasajes: "Porque no narré todo a locas: sólo los apuntes principales, lo que puedo creer. No desperdicio palabras; el mono mío viste ropas. Usted piense, usted sienta. Usted ponga la trama" (p. 234).

\subsection{El método es objetivador}

Aquí es relevante considerar la polarización entre el narrador y el actor, ya apuntada anteriormente. La distancia entre ambos es advertida por Riobaldo, que objetiva al personaje: "Por ahí, entonces, necesita que usted escuche bien estos pasajes: de la vida de Riobaldo, el jagunço (...) El jagunço Riobaldo. ¿Fuí yo? Fuí y no fuí ¡No fuí! - porque no soy, no quiero ser" (p. 166). O los personajes: "Fuí el jefe Urutu-Branco - después de ser Tatarana y de haber sido el jagunço Riobaldo. Esas cosas largué, me largaron en lo remoto (...) Otra razón, otros tiempos" (p. 412). 
Todorov, al analizar los problemas de la "visión" de la primera persona en el relato, formaliza las relaciones entre el sujeto y el objeto de la narración de la siguiente manera: "Desde el momento en que el sujeto de la enunciación se convierte en sujeto del enunciado, ya no es el mismo sujeto quien enuncia. Hablar de sí mismo significa no ser ya el mismo "sí mismo"31. Riobaldo dice lo mismo de otra manera: "Un sentir es del sintiente, pero otro es el del sentidor" (p. 237) - extraordinaria fórmula crítica y poética que resume la objetivación que el "yo" narrador (sintiente) en el presente opera sobre el "yo" personaje (sentidor) del pasado.

Al final de su relato, Riobaldo intenta diluír la polarización de los dos "yos", conduciendo al actor junto al narrador, al nivel de la narrativa "B":

Esto no es lo de relatar pasajes de su vida, en toda admiración.

Como lo que fuí y ví, al levantar el día. (p. 460; el subrayado es mío).

\subsection{El método es presentificador}

La narración en pretérito imperfecto lleva a la percepción del presente (vide item 3.2). Aquí nos interesan los índices de percepción de presentidad del crítico Riobaldo. Cuando dice: "Yo me acuerdo de cosas antes que ellas ocurran" (p. 27), significa no sólo la percepción del desorden cronológico que realiza sobre la materia, sino también el propósito de crear una "ilusión" de presente en el interlocutor (lector). Decir ocurrieran es fingir un futuro que no se realizará jamás para "las cosas", pero es significar, eso sí, el futuro del acto de narrar, que instaura una nueva dimensión de la realidad. El sucederse de los hechos se debe dar por (y para) el acto de la narración; nada debe ser revelado antes de la hora (como la identidad de Diadorim) y hasta aún el tamaño de una carta:

Escribí la mitad. Es decir: ¿Cómo es que podía saber que era la mitad, si yo no tenía aún toda la carta pronta para medir? Ah, ¿vió?

(p.370).

Aquí, la presentificación por el contar involucra hasta el narrador, que más adelante confiesa haber completado la otra mitad: “... que la carta, aquélla, solamente terminé de escribir, y mandé, casi en la fecha de un año mucho después..." (p.370). En el entusiasmo de describir bien una batalla entre jagunços, en medio del pretérito, escapa una forma presente: "Soy Zé Bebelo?" (p. 419), que a veces también puede indiciar el andamiento temporal del enunciado: "Atrás, el niño Guirigó, envejeciéndose..." (p. 423).

\subsection{El método es tensionador}

El narrador se sabe poseedor de una buena historia para contar y los grandes lances son cuidadosamente reservados para lograr los efectos deseados. Todos los acontecimientos confluyen para la revelación final de la identidad de Diadorim, "clave" del relato, que realiza la distensión sobre 
la tensión creada a partir de elementos indiciadores de la feminidad del amigo. Si en el plano de la historia hay elementos que motivan el interés del interlocutor, en el plano del discurso también hay signos específicos de "contención" de la materia:

Usted ya que oyó hasta aquí, siga oyendo. Porque está llegando la hora de tener que contarle cosas muy extrañas (pp. 288-89).

Sobre así, ahí corría en medio de los nuestros un acuerdo de animación, hecho que a usted se lo demoré: debido a que mismo un contador habilidoso no encuentra modo de relatar todas las peripecias de una vez. (p.315)

Buen contador, Riobaldo sabe fiscalizar las eventuales impaciencias del interlocutor: "Hablo con palabras erradas. Cuento mi vida que no entendí. Usted es hombre muy ladino, de instruída sensatez. Pero no se veje, no quiera lluvia en el mes de agosto. Ya cuento, ya vengo- hablar del asunto que usted está de mí esperando. Y escuche" (p.370). También el uso de preguntas estratégicamente colocadas entre los acontecimientos motivan el interés del interlocutor: "¿Qué era lo que yo intentaba hacer? Usted espérese" (p.368) o sobre el proyecto de cruzar el Liso de Sussuarão, cuando era jefe: “ ¿Todos me entendieron? (...) ¿Me siguieron?" (p.382); la pregunta también es signo de constante afirmación que repasa la narrativa de la que ella es un diálogo. En este sentido, se presta sobremanera para reactivar la atención del interlocutor, frente a la amenaza de un posible descenso de la tensión, después del relato de un acontecimiento capital, como es el Juicio de Zé Bebelo:

¿Cómo es que yo iba a poder tener presentimiento de las cosas terribles que vinieron después, conforme usted va a ver, que ya le cuento? (p.217)

\subsection{El método es ficticio}

Este es, dentro del análisis del método, el punto culminante de algo que quedaba latente en los 2.1. y 2.5. Se contradecía en 2.2., para reforzarse en 2.6.: la sumisión de la realidad a la ficción ${ }^{32}$. Ahora, la veracidad de lo vivido se enfrenta con el problema de ser sometida al acto de representación verbal. El discurso de Riobaldo guarda conformidad apenas con sus propias leyes (fácilmente enumerables) y que pueden ser reducidas a una sola: la comunicación con el interlocutor (contar para tener una respuesta). Fiel a su norma de verosimilitud, el narrador es, con todo, consciente de ese imposible narrativo: reproducir lo (su) real: "Lo que yo hablé ¿fue exacto? Fue, ¿pero habría sido? Ahora me parece que ni era asi" (p.142). La solución está en redefinir lo real:"Uno vive repetido, lo repetido, y, resbaladizo, en un mi-minuto, ya está recostado en otra rama (...) Digo: lo real no está en la salida, ni en la llegada: se dispone para uno en el medio de la travesía" (pp. 51-52). La travesía (lo real) es el propio discurso, por eso el realismo de Riobaldo consistiría en usar un método de prospección de su vivido 
coherente con su propia naturaleza (recordemos: la materia es "vertiente"). Autor y lector de su relato, Riobaldo se sitúa en dos polos de la visión realista (revolucionaria) que propone Jakobson, en su conocido examen de las significaciones del término realismo en la crítica:

$\mathrm{A}_{1}$ : la tendencia a deformar los cánones artísticos en vigencia, interpretada como una aproximación a la realidad.

$\mathrm{A}_{2}$ : la deformación de los cánones artísticos es reconocida como una aproximación a la realidad ${ }^{33}$.

Uno de los "casos" ejemplares que el narrador cuenta al doctor es el de los jagunços Davidão y Faustino, que hicieron un pacto: este, por diez contos de reis, substituiría a aquél en la hora de la muerte. Con todo, la situación límite nunca se realizó... en la vida. Riobaldo cuenta el caso a un "muchacho de ciudad grande, muy inteligente", el que le adapta un "final sustancioso, esmerado" (cfr. p. 67). Analizando ese remate imaginario, Riobaldo teoriza sobre la vida y la ficción: ésta tiene "otros movimientos, sin los errores y las reviradas de la vida en su lentitud de embarullar"; "en lo real de la vida - prosigue - las cosas acaban con menos formato, a veces ni acaban" (p. 67). Compárese esta teorización de Riobaldo sobre la Literatura, con ésta de Antonio Cândido, al confrontar el homo fictus con el homo sapiens:

(...) una de las funciones capitales de la ficción, es la de darnos un conocimiento más completo, más coherente que el conocimiento decepcionante y fragmentario que tenemos de los seres. Aún más: el poder comunicarnos este conocimiento. De hecho, dada la circunstancia de ser el creador de la realidad que presenta, el novelista, como el artista en general, la domina, la delimita, la muestra de modo coherente, y nos comunica esta realidad como un tipo de conocimiento que, en consecuencia, es mucho más cohesivo y completo (por lo tanto más satisfactorio) que el conocimiento fragmentario o la falta de conocimiento real que nos atormenta en las relaciones con las personas 34 .

Por otro lado, es significativo que Riobaldo tenga ciencia sobre la profunda naturaleza del acto narrativo, pues la referencia al proyecto de ficción del muchacho sólo remite a su propio proyecto de contar: dar formato y movimiento a su materia. Y para esto la imaginación debe aliarse a la memoria: "... usted msimo nunca vió cosa así, sólo mismo en novela descrita” (p. 103). “UUsted teje? Entienda mi figurado” (p. 142). La palabra fantasía define su narrativa: "La fantasía, mía ahora, en esta charla..." (p. 188). "Lo que siento, y me esfuerzo en decirle a usted, respondo por mis recuerdos, no consigo; por tanto es que refiero todo en estas fantasías" ( $p$. 219). "Sólo estas mis artes de decir-las fantasías..."(p. 422). 
Sobre la posible parcialidad en la visión de los hechos, él dice también:

Así exacto es lo que fue, juro a usted. Otros son los que cuentan de otra manera (p. 331: se refiere a la manera como asumió la jefatura del bando de jagunços).

Uno de los buenos índices de la falla de memoria de Riobaldo es la piedra: es "amatista", después "zafiro", hasta que corrije: "Esto es: ¡la piedra era de topacio! - sólo en el bocal de la idea es que me equivoco y lo cambio todo confuso así" (p. 430). Sus vacilaciones, el constante preguntar, afirmar y negar, alcanza etapas de máxima lucidez; al punto de advertir la proyección de sus dudas en su interlocutor: "El sertão me produjo, después me tragó, después me escupió caliente de la boca... ¿Usted cree en mi narración?" (p. 443).

Hay dos notables alusiones a los acontecimientos vividos por Riobaldo y sus jagunços: la primera está en lo que dice Riobaldo durante el juicio (uno de sus argumentos más sólidos a favor de la absolución es que la vida del grupo será convertida en relato y los jagunços, personajes de una historia honrada) (cfr. p. 209); la segunda es la propuesta de Zé Bebelo, al final, de ir juntos a la ciudad y contar los hechos del sertão. Riobaldo se niega y se justifica: "Distraer a la gente con mi nombre..." (p. 459). Con esto, el narrador acentúa la proposición inicial de un compromiso ineludible de quien lo oye o lee. Riobaldo nos obliga a este nuevo pacto suyo: participar de su historia, dialogar con él; niégase al mero relato para el ocio y exige una postura crítica (respuesta) del lector.

La mejor expresión de la conciencia crítica del narrador sobre la naturaleza ficticia de su acto de contar está en el cierre precioso que le da a él: una fórmula típica de los relatos populares de imaginación:

Aquí se acabó la estoria.

Aquí, la estoria acabada.

Aquí acaba la estoria. (p. 454).

En donde la palabra "historia" que venía usando es substituída por "estoria", (término inventado por Guimarães Rosa para significar "cuento") para oponerse, justamente, a "historia", al fin mucho más condicente con las "fantasías" de Riobaldo.

La última referencia a la cuestión de la naturaleza de su operación narrativa está en la última página de la novela. Allí Riobaldo restituye a la realidad su diezmo, recolocándola junto a lo inventado:

Y me cierro, aquí, mire y vea. Esto no es lo de relatar pasajes de su vida, con toda admiración. Cuento lo que fuí y ví, al levantarse el día. Auroras. Cierro. Usted ve. Conté todo. (p. 460).

En este ejemplo fui alude a lo real, lo vivido, y ví a la distorsión de lo real, la visión deformadora del narrador. 
Dejamos el aspecto ficticio para el análisis final del método, una vez que se puede integrar a los demás, abriendo una solución para la ambigüedad propuesta a lo largo de la novela, al nivel de la narración: ¿contar reproduce o desvirtúa lo real (vivido)? El péndulo oscila más para el último lado. Y, aunque esto pueda parecer obvio para el lector (crítico), es fruto de demorado y costoso proceso de cuestionamiento del narrador-crítico. Así, no es importante, para este trabajo, la comprobación de que Riobaldo no presenta, sino representa los hechos.Lo importante es la comprobación que Riobaldo dice que representa ${ }^{35}$.

La intención mimética, aunque afirmada en 2.2. y 2.4., entra en crisis con la (des) ordenación, tensión y selección de la materia. Lo verdadero, lo real, sólo existe, con plenitud y exclusivamente en Grande sertão por el presente del narrador, por el acto de representación verbal, o según Riobaldo, "en medio de la travesía".

\section{EL CODIGO DEL INTERLOCUTOR}

\subsection{Aspectos de la recepción (signos del narratario)}

Ya se dijo repetidas veces que Grande sertão es un falso diálogo pues el doctor nada dice y toda el habla está representada por el narrador. Decir que Grande sertão es un monólogo es reducir a nada el nivel de la narrativa "B", es despojar de significación el habla crítica de Riobaldo, es negar el propio sentido de su acto de elocución. Toda el habla del narrador contiene la de su interlocutor - y el empleo de este término ya significa hacer del doctor un hablante: ya que no es un mero oyente, callado y atento. Para nosotros Grande sertão es, cabalmente, un diálogo, pues la participación del doctor aparece registrada en el relato. No importa que la escritura no le haya dado un lugar espacialmente configurado, o sea, no coloque su habla después de un guión (y eso se podría hacer, si reescribiésemos la novela, sin alterarla en nada). Es claro que Riobaldo habla mucho más - pero él nunca está solo, vuelto hacia su monológo. Es él mismo quien lo dice: "... en esta charla mía, nuestra de relato" (p. 340 , el subrayado es nuestro). Nos interesará mostrar aquí cómo el interlocutor es registrado por el narrador.

El primer paso es la caracterización del interlocutor. ¿Quién es ese doctor? Es persona instruída, y "sesuda" (p. 11), de alta opinión, que sabe mucho (p. 22), de ideas firmes y tiene título de doctor (p. 22); es hombre "sobrevenido, sensato, fiel como papel" (p. 79), "sagaz, mañoso" (p. 176); "muy ladino, de instruída sensatez" (p. 370). Es posiblemente un pesquisador del territorio del sertão, pues "pretende atravesar a raso el territorio del sertão, con el fin de conferir lo que existe" (recordando al alemán Alquiste u Olquiste de "Recado do Morro"). Tal vez haya oído hablar de las guerras entre jagunços y quiera recoger material, pues Riobaldo le dice que los tiempos cambiaron, que ya no existe la valentía: "Tiempos fueran, las costumbres mudaran" y hasta el ganado es más educado (p. 23). Su interés está en un "montón razonable de bizarrerías" y Riobaldo le sugiere emprender viaje más "dilatado". El y Riobaldo tienen un 
conocido en común: es el alemán Emilio Wusp (cf. p. 57).

El interlocutor entra en el espacio de la locución cuando Riobaldo está echado bajo un árbol del quintal de su casa y le cuenta el nacimiento de un extraño animal, allí en las redondezas, "con cara de persona, cara de perro", que es luego asociado al demonio. El doctor se ríe de la historia (p. 9). La visita ocurre un martes y después de oír unos "casos" de Riobaldo y una mención a Diadorim quiere irse. Pero Riobaldo sé lo impide:

Eh, ¿que se va? Pues que no. Hoy, no. Mañana, no. No consiento.

(p. 22).

Y se acaba quedando por tres días (martes, miércoles, jueves de mañana) para oír la historia de Riobaldo, el jagunço. Esa historia tiene un largo preámbulo antes de ser realmente iniciada, cuya función es la de establecer la finalidad del relato: el interlocutor debe oírlo, "pensar y repensar" y después recontar, para ayudarlo (cf. p. 79). Inicialmente la respuesta que exige Riobaldo se refiere a la existencia del demonio, que en el curso de la narración, recibe variantes, como el por qué del encuentro con Diadorim (pp. 86-87), o del deseo de matar a Hermógenes (p. 131), etc. A cierta altura, el compromiso es mucho más amplio: "Lo que quiero es armar el punto de un hecho, para después pedirle un consejo" (p. 166). "Le cuento a usted lo que yo sé y usted no sabe; peor lo principal que quiero contar es lo que yo no sé si sé y que puede ser que usted sepa" (p. 275). La finalidad del contar sufre una tercera alteración en el curso de la novela: el interlocutor comienza a anotar lo que oye (p. 220) ; a partir de ahí la finalidad pasa a ser la escritura de lo narrado. Las referencias a la libretita del doctor demuestran el empeño de ambos en esta nueva meta:

La Guararavacã del Guaicuí: usted tome nota de ese nombre. (p.220).

Mismo sólo igual a lo que pudiese dar el cajueiro-enano y el araticum, que - de acuerdo a lo que usted por escrito apuntará abundan en esos campos. (p. 363).

Usted escriba en el cuaderno: siete páginas... Aquellos urucuianos no iban en busca (...). (p.378).

Campos de Tamanduá - tan - usted escriba ahí: veinte páginas ... (p. 413).

Usted llena una libretita. (p. 451).

La presencia de esa libretita substituye al deseo de respuesta, de repensar, de ayuda o consejo iniciales por un afán de obtener una elaboración o mejoramiento de lo que cuenta a través de la escritura:

Usted piense, usted conciba. Usted ponga el enredo. (p. 234).

Conforme pasó. Yo cuento; usted me pone punto. (p. 401).

También el comportamiento del doctor se va modificando durante la narración. Si al comienzo, al oír hablar del diablo, "dió unas risas", volvióse más serio después cuando Riobaldo habla del pacto: "Veo que usted no se rió, ni aún teniendo ganas" (p. 310) - Riobaldo necesita una actitud com- 
prensiva de su interlocutor - y es significativo que espere por ella para dar comienzo ordenado al relato, para proseguir después la descripción del encuentro con el Niño: "ahora por la forma de quedarse callado, veo que usted me sigue" (p. 87). De la "atención" inicial (p. 79), el doctor pasa a una "devoción", que hasta obliga al narrador a ordenar la materia: "Ahora, en este día nuestro, con usted mismo - escuchándome con una devoción así - es que a poco voy aprendiendo a contar corregido" (p. 152). La gran conquista de la narración es la alianza (otro pacto?) progresivamente ambos: "Vivir...usted ya sabe: vivir es etcétera..." (p. 74). "Lo que me mortifica de tanto hablar, usted sabe. El diablo" (p. 385). Durante la charla en que toman café y pitan cigarros la colaboración es estrecha y mutua: tanto el doctor presta atención y da sus respuestas cuanto el narrador participa de las anotaciones en la libretita (vide supra). Llega hasta a orientar el trazado del lugar de la batalla final contra Hermógenes: "Usted haga una cruz, trace. Que tenga" cuatro brazos (...)" (p. 414). Otro aspecto del comportamiento del interlocutor es el cansancio, que está registrado así por Riobaldo: "Hablo mucho, lo sé; harto" (p. 108). "De contar todo lo que fue, me retiro, usted está cansado de oír narración (...)" (p. 230).

Para completar el examen de los signos del interlocutor, nos queda considerar las respuestas indicadoras de "habla" del doctor, así como las preguntas que son registradas por el narrador. El primer signo de su habla está dado por la respuesta a la existencia del diablo: "Pero, ¿no diga que usted, sesudo e instruído, que cree en la persona de él? ;Le agradezco! Su alta opinión compone mi valía. Ya sabía, la esperaba (...)" (p. 11). Una pregunta de Riobaldo registra una solicitación del interlocutor: "Adelante? Cuento" (p. 87). El narrador se deja orientar por el interlocutor, que propone interrupción o continuidad: "Usted quería saber más? No. Yo sabía que no" (p. 176, subrayados míos). Riobaldo se olvida de la letra de la canción del Siruiz y pregunta: “¿Usted se acuerda de la canción del Siruiz? (p. 236). La respuesta del doctor aparece indicada mucho después: "Así, aquella otra - la que usted dijo: canción del Siruiz (...)" (p. 412). No siempre, sin embargo, hay registro de las respuestas del interlocutor, y la pregunta tiene una función fáctica apenas: "A lo que digo a usted, pregunto: ien su vida es así?"'(p. 98). "Loque yo hablé ¿fue exacto? Fue. Pero ¿habría sido?" (p. 142). "¿Por qué era que yo estaba procediendo a tontas así? Usted, diga: ¿lo sé?" (p. 51). Motivadoras del interés, mantenedoras del contacto, muchas preguntas quedan sin respuesta en el texto, esperando la del lector. Como éste está representado en el diálogo por el interlocutor, el narrador le ofrece al doctor una pregunta que puede ser la nuestra: "Usted pregunte: ¿quién fue que fue que fue el jagunçoRiobaldo?" (p. 236).

\section{LOS TIEMPOS VERBALES}

Habíamos comprobado (2.1) que la percepción del (os) signo (s) de narratividad dependía del nivel (" $A$ " o " $B$ ") en que se colocaba el lector. Esas variaciones de percepción están íntimamente ligadas al empleo de los 
tiempos verbales: la polarización del actor por el narrador se realiza, con plenitud, por los diferentes tiempos verbales utilizados. El nivel de la narrativa "A" aparece en el pretérito, sobre todo imperfecto, y el nivel " $B$ " aparece en el presente. Ahora bien, nuevas modalidades de percepción se articulan cuando la lectura establece la mudanza de " $A$ " para " $B$ " y viceversa. Resumiendo, hay dos percepciones de temporalidad del enunciado:

1. presente (narrativa " $A$ ", a través del uso del imperfecto).

2. pretérito (narrativa "B"; se deshace la ilusión de presente de " $A$ ", por la distancia entre el narrador y el actor).

El lector, cuyo sistema espacio-temporal es definido por el grado cero, advierte el imperfecto como un presente, debido a la ambigüedad de aquél en cuanto a la conclusión de un acto. Käte Hamburger, en sus criteriosos estudios sobre el pretérito épico, observa la pérdida de la función del imperfecto en la ficción. Para ella, ese tiempo verbal retrata situaciones actuales, y así se anulan las distancias entre los personajes, los hechos y el destinatario del relato ${ }^{36}$. Por otro lado, sólo cuando surge en la escena el narrador representado es que el lector se da cuenta de que era víctima de una ilusión. Paradojalmente, cuando Grande sertão dice pasado, la percepción es del presente y cuando dice presente, no éste, sino el tiempo anterior se plantea como pasado. En la relación personaje-lector tenemos:

1. uso del pretérito - anulación de la distancia entre Riobaldo personaje de "A" y el lector;

2. uso del presente - establecimiento de la distancia entre Riobaldo, personaje de " $\mathrm{A}$ " y el lector.

La actualización conseguida por el imperfecto es tan eficaz para la mencionada "ilusión de realidad" que al propio narrador se le escapa una frase como: "Pensé que ahora podíamos merecer más descanso" (p. 104 - en que ahora equivale a "en aquella ocasión", habiendo así una alteración en la referencia del adverbio.

El continuo desplazamiento del lector para el presente y pasado, alternadamente, resulta en el barajamiento de las esferas de presentidad y preteridad. Las dimensiones temporales se confunden y sería más correcto admitir que Grande sertão permite una percepción de la atemporalidad, del fluir constante, en que los tiempos verbales se sumergen. El propio Riobaldo reduce las dimensiones del tiempo, diciendo: "Conmigo, las cosas no tienen hoy y anteayer-mañana: es siempre" (p. 109). Al final de su relato hay una fórmula que significa ese encuentro prodigioso de los tiempos:

Aquí acabó la estoria.

Aquí, la estoria acabada.

Aquí acaba la estoria. (p. 454). 
Este cierre sintetiza la conducción del pretérito para el presente de la narración. Con acabó / acabada / acaba se disuelve la polarización mantenida por el narrador: sólo queda de ahora en adelante el puro presente del acto de locución. Si en este punto del relato se destruye la ilusión de presentidad de " $A$ ", hay otra que se mantiene hasta el fin: la forma dialógica de la narrativa "B", al proponer su aqui y ahora, aproxima al lector, cuyo sistema acaba por confundirse con el de los dialogantes.

\section{EL CANJE DE FUNCIONES}

Para concluir, podemos decir que Grande sertão realiza, al nivel de la narración, un canje de funciones entre los elementos de la comunicación narrativa, sin paralelo tal vez debida a la explicitación del metalenguaje. El esquema básico de tales permutaciones consiste en:

$\mathrm{N}$ - narrador (emisor) representado $=$ Riobaldo

I- narratario (destinatario) representado $=$ interlocutor-doctor.

Como nosotros, lectores, también somos destinatarios del mensaje, resulta el primer canje:

Interlocutor $=$ lector $(\mathrm{I}=\mathrm{L})$.

Ahora bien, si admitimos con Wayne Booth ${ }^{37}$ la actualización en el relato de un "autor implícito" $\left(A_{1}\right)$ - versión literaria o representación del autor real, o un "segundo yo" del autor - veremos que, con rigor, es Riobaldo el narrador. Pero la presencia del interlocutor-doctor confunde tal identificación, una vez que éste crea en el lector la ilusión de un autor que habría organizado en escritura el habla de Riobaldo (vide en 3.1. los informantes del registro escrito del doctor). La resultante es:

Narrador $=$ Autor Implícito $\left(\mathbf{N}=\mathbf{A}_{1}\right)$

Interlocutor $=$ Autor Implícito $\left(I=A_{1}\right)$

Si el lector asume la función de interlocutor en la comunicación del relato y éste es un personaje $(\mathrm{I}=\mathrm{P})$ y autor implícito, ocurre lo siguiente:

Lector $=$ Autor Implícito $\left(\mathrm{L}=\mathrm{A}_{1}\right)$

Lector $=$ Personaje $(\mathrm{L}=\mathrm{P})$

En cuanto al polo del narrador, otra consecuencia es notable: al ser Riobaldo un crítico, ejerciendo su metalenguaje al nivel $B_{3}$ es, por eso mismo, un lector de su relato ${ }^{38}$. Así:

Narrador $=$ Lector $(\mathrm{N}=\mathrm{L})$

Por otro lado, al estar representado el narrador, él es un personaje de la narrativa "B". Resumiendo, entonces:

\begin{tabular}{|c|c|c|c|}
\hline & EMISIÓN & & CEPCIŌ \\
\hline & & $I=L$ & \\
\hline
\end{tabular}


Como el lector asume las funciones del interlocutor, sucede que:

$\mathrm{L}=\mathrm{A}_{1}$ por lo tanto, $\mathrm{A}_{1}=\mathrm{P}$
$\mathrm{L}=\mathrm{P}$

La más sorprendente ilusión ofrecida por Grande sertão proviene de los canjes anteriores: nosotros, lectores, también somos donantes del relato ${ }^{39}$ :

$\mathrm{L}=\mathrm{N}$

Al nivel narracional de Grande sertäo se anulan las distancias, de cualquier tipo, entre los polos de la comunicación narrativa. Todos, narrador, interlocutor, lector, pueden ser todos en esa "charla de relato". El extraordinario logro poético proporcionado por ese radical cuestionamiento del acto narrativo - principio rector de la renovación de la novela latinoamericana en este siglo - actualiza un rol de experiencias de la narración que van de los orígenes de la ficción narrativa hasta el día de hoy. Las tradicionales oposiciones - presente-pasado, yo-él, monólogo-diálogo, oralidad-escritura, realidad-imaginación, lenguaje-metalenguaje, en Grande sertão dan lugar a una forma nueva que, al operar una compleja nodisjunción narracional, aprovecha las conquistas ficcionales de todos los tiempos.

Universidade de São Paulo

IRLEMAR CHIAMPI CORTEZ

NOTAS

\footnotetext{
*jagunço: hombre del sertão que protege o defiende a una persona, mediante un sueldo o beneficio.

${ }^{1}$ Roland Barthes: "Introduction à l'analyse structurale des récits", en: Communications, No. 8, Paris, Du Seuil, 1966, p.21.

2 João Guimarães Rosa: Grande Sertao: Veredas, Rio de Janeiro, Jose Olympio, 1968, 6a ed., (la primera es de 1956), p. 260. (Las indicaciones de páginas remitirán a esta edición).

${ }^{3}$ W. Kayser habla de "narrativa enmarcada" (Rahmenerxăhlung), cuya función-según él es dar credibilidad a los hechos narrados e intensificar la situación primitiva de todas las narrativas (cf. W. Kayser: Interpretación y análisis de la obra literaria, Madrid, Gredos, 1961, $4^{\mathrm{a}}$ ed., p. 262).

${ }^{4}$ Cf. 3.2., aquí.

${ }^{5}$ Cf. op.cit., pp. 261 y 265.

${ }^{6}$ Op. cit., p. 22.

${ }^{7}$ Op. cit., p. 470.

${ }^{8}$ Con esto se refuerza la atmósfera "medievalesca" o "antigua" de Grande Sertăo - tan estudiada ya a nivel de los personajes y acontecimientos por la crítica roseana. Es característica de las sociedades "arcaicas" la fuerte codificación del relato - nos informa Barthes, que agrega: "Mais pour le courant, notre société escamote aussi soigneusement que posible le codage de la situation de récit (...) La répugnance à afficher ses codes marque la société bourgeoise et la culture de masse qui en est issue: à l'une et à l'autre il faut des signes qui n'aient pas l'air de signes" (op.cit., p.22). El código narracional de Grande Sertao está cerca así de relatos como Il Decamerone, de Boccaccio, The Canterbury Tales, de Chaucer, o Las Mil y una noches.
} 
${ }^{9}$ R. Barthes, op.cit., p. 22.

10 "El tema de la épica es el pasado como tal pasado: háblasenos en ella de un mundo que fue y concluyb" (Ortega y Gasset, Meditaciones del Quijote, en Obras, de J. Ortega y Gasset, Madrid, Espasa Calpe, 1943, $3^{\mathrm{a}}$ ed., p.55).

${ }^{11}$ Respectivamente "Die Ich Erzahlsituation" y "Die Personale Erzahlsituation". F.K. Stanzel, Typische Formen des Romans, Gottingen, Van der Koek en Ruprechts, 1964, p.16, apud F. van Rossum-Guyon, "Point de vue ou perspective narrative", en: Poétique, nº 4, Paris, Du Seuil, 1970, p.488.

${ }^{12} \mathrm{~T}$. Todorov: "Poética", en: O. Ducrot et alii, ¿Qué es elestructuralismo?, traducción de $\mathbf{R}$. Pochtar y A. Pirk, Buenos Aires, Losada, 1971, pp.125-126.

${ }^{13}$ M. Cavalcanti Proença: Trilhas do Grande Sertdo, Cadernos de Cultura, Ministério de Educação e Cultura, Rio, 1958.

${ }^{14}$ Cf. OMundo Movente de Guimarães Rosa, São Paulo, Editora Atica, 1972, pp. 46-48.

${ }^{15} \mathrm{La}$ coordinación a que nos referimos, vale la pena insistir, es entre las grandes unidades del relato; aunque entre las oraciones prevalezca tal proceso, la regla de combinación de los niveles sólo la niega.

${ }^{16} \mathrm{~T}$. Todorov: "Les catégories du récit littéraire". en Communications, no 8, Paris, Du Seuil, 1966, p. 140.

${ }^{17}$ Roberto Schwarz: "Grande Sertão: a fala", en: A Sereia e o Desconfiado, Rio, Ed. Civilizaçāo Brasileira, 1965, p.25.

${ }^{18}$ Idem, ibidem, p.25.

19 R. Barthes: Le dégré zéro de l'écriture, Paris, Du Seuil, 1953, p.32.

${ }^{20}$ "Chacune/escritura/ désormais, la travaillée, la populiste, la neutre, la parleee, se veut l'acte initial par lequel l'ecrivain assume ou abhorre sa condition bourgeoise. Chacune est une tentative de réponse à cette problématique orphéenne de la Forme moderne: des écrivains sans Littérature (...) Chaque fois que l'écrivain trace un complexe de mots c'est l'existence même de la Littérature qui est mise en question; ce que la modernité donne à lire dans la pluralité de ses écritures, c'est l'impasse de la propre Histoire." (idem, ibidem, pp.87-88).

${ }^{21}$ W. Nogueira Galvão: As Formas do Falso; un estudo sobre a ambiguidade no Grande Sertão: Veredas, São Paulo, Ed. Perspectiva, 1972, p.71.

22 R. Barthes: Elements de sémiologie, Paris, Du Seuil, 1964, Cap. IV.

${ }^{23}$ J.P. Vernant: "Aspects mythiques de la mémoire en Grèce", en: Journal de Psychologie, 1959. p.7, apud Mircea Eliade, Aspects du mythe, Paris, Gallimard, 1963, p.149.

24 Véase el item 2.10. otra referencia a la oposición ficción-vida.

${ }^{25}$ No se trata de los "casos" o de las "interpolaciones de cuentos" en la novela, cuya función de ejemplaridad ya fue bien analizada por J.C. Garbuglio, op.cit. , cap. II, parte 4. 88.

26 Cf. R. Barthes: "L'effet de réel" en: Communications, no 11, Paris, Du Seuil, 1968, pp. 87-

${ }^{27}$ Augusto de Campos los llama "musicales", buscando semejanzas con la tematización musical de Joyce en Finnegans Wake, cf. "Um lance de 'dês' do Grande Sertđo", en: Pedro Xisto et alii, Guimarães Rosa em Três Dimensóes, Com. Est. de Cultura, São Paulo, 1970, p. 53.

28 "... Los niveles de conciencia anteriores a la palabra humana no aparecen censurados, controlados ni ordenados lógicamente". R. Humphrey, Corriente de la conciencia en la novela moderna, traducción de J. Rodríguez Puértolas y C.C. Rodríguez Puértolas, Santiago de Chile, Editorial Universitaria, 1969, p.13; cf. supra, 1.3.

${ }^{29} \mathrm{El}$ término es de Jean Pouillon (Vide Tiempo y novela, traducción Irene Cousien, Buenos Aires, Editorial Paidós, s.f., pp.37-56).

${ }^{30}$ La palabra viene aquí entre comillas por estar empleados en el sentido erróneo que la tradición crítica le atribuye: reproducir la realidad fielmente. Vide discusión del problema en 2.8

31 T. Todorov: Poética, en: op.cit. p.125.

${ }^{32}$ Es preciso insistir: el concepto de realidad aquí usado se aplica a lo "real" de Riobaldo, el narrador ("vida", "vivencia", "las cosas que formaron el pasado", lo "vivido"), que para nosotros, lectores, será siempre hipotético.

${ }^{33} \mathrm{R}$. Jakobson: "Du réalisme artistique", en: Théorie de la littérature; Textes de formalistes 
russes, Paris, Du Seuil, 1965, p.102.

${ }^{34}$ Antônio Cândido: "A personagem do romance", en: Antônio Cândido et alii, A Personagem de Ficção, São Paulo, Perspectiva, 1968, p.64.

35 Un ejemplo curioso de ese metalenguaje que afirma lo imaginario e instaura un nuevo "real", lo tenemos en "A hora e a vez de Augusto Matraga": allí el narrador interrumpe la narración para destruir la "ilusión realista" del lector: "E assim se passaram pelo menos seis ou seis anos e meio, direitinho deste jeito, sem tirar nem pôr, sem mentira nenhuma, porque esta aqui é uma estória inventada, e nãoé um caso acontecido, não senhor." J. Guimarães Rosa, en: Sagarana, Rio, Jose Olympio, 1968, $10^{\mathrm{a}}$ ed., p. 338.

36 K. Hamburger: Die Logik der Dichtung, Stuttgart, Ernest Klett Verlag, 1957.

37 Cit. por F. van Rossum-Guyon, art.cit., p.483.

${ }^{38}$ También el "Compadre meu Quelemém" es un lector del relato de Riobaldo. Todas las referencias del narrador a él lo muestran como un ex-interlocutor y un crítico del (o de un) discurso de Riobaldo.

${ }^{39}$ Por lo demás, queda abierta la posibilidad de que yo, lector, como el doctor-interlocutor, reproduzcamos la historia (estoria) de Riobaldo, el jagunço. 